\title{
Factors Associated With the Concentration of Visceral and Subcutaneous Fat
}

Cláudia Porto Sabino Pinho*, Alcides da Silva Diniz, Ilma Kruze Grande de Arruda, Ana Paula Dornelas Leão, Emídio Cavalcanti de Albuquerque and Isa Galvão Rodrigues

University of Federal de Pernambuco, Brazil

\begin{abstract}
Background: The abdominal adipose tissue has deposits of subcutaneous and visceral fat, which, in excess provides different risks to metabolic and hemodynamic changes.

Objective: Assess factors associated with the concentration of visceral and subcutaneous fat.

Methods: Case series study involving 109 overweight outpatients in the Brazilian northeast. Visceral and subcutaneous fat was assessed by CT scans. Demographic and clinical covariates, lifestyle and body mass index (BMI) were analyzed.

Results: The average age was $50.3( \pm 12.2)$ years. Men showed a higher concentration of visceral fat compared to women $(p<0.001)$. In the multivariate analysis, the presence of arterial hypertension $(\mathrm{AH})$, higher BMI and lower intake of protective food among men was associated with the highest concentration of visceral fat (adjusted $\mathrm{R}^{2}: 46.4 \%$ ) and $\mathrm{AH}$, a higher education (in years), a higher BMI and lower consumption of oils and fats were significantly associated with subcutaneous fat (adjusted $\mathrm{R}^{2}$ : $88.6 \%$ ). For women, age, $\mathrm{AH}$, high $\mathrm{BMI}$ and alcohol consumption were associated with VAT (adjusted $\mathrm{R}^{2}=17.6 \%$ ) and high BMI, high education, a higher consumption of fatty and processed meats and a lower consumption of simple carbohydrates were associated with SAT (adjusted R²: 69.3\%).
\end{abstract}

Conclusion: Multiple different factors determine and their complex inter-relationships determine the amount of visceral and subcutaneous fat in men and women.

Keywords: Visceral fat; Subcutaneous fat; Life style; Food consumption; Adult; Age

\section{Introduction}

Obesity is a serious public health issue, reaching epidemic proportions with a great impact on the pattern of adult morbidity and mortality $[1,2]$. Excess abdominal fat is a better predictor of high coronary risk compared to generalized obesity, standing out as an independent factor of cardiometabolic risk $[1,3]$. The abdominal adipose tissue has deposits of subcutaneous and visceral fat, which, in excess, provides different risks to metabolic and hemodynamic changes [4]. This heterogeneous nature of abdominal adipose tissue compartments reflects the differences related to anatomical characteristics, morphology of adipocytes, endocrine function, lipolytic activity, vascularization and innervations [5,6]. Approximately $80 \%$ of all body fat is arranged subcutaneously, deposited primarily in gluteo femoral regions, in the back and in the anterior abdominal wall. The visceral fat is $10-20 \%$ of the total fat in men and $5-8 \%$ in women $[4,5]$.

Due to its anatomic position, the venous drainage of the visceral adipose tissue (VAT) is performed by the portal circulation directly to the liver, differently from the subcutaneous adipose tissue (SAT), whose venous drainage occurs by systemic circulation $[5,6]$. The portal drainage of VAT provides direct access of free fatty acids and adipokines secreted by visceral adipocytes $[5,6]$. This is the epicenter of a great number of hypotheses postulated to explain the association between visceral fat and cardiometabolic diseases [5,6]. Adipokines activate immune hepatic mechanisms to produce inflammatory mediators [5]. An increased flux of free fatty acids to the liver promotes increased insulin resistance and an increased production of triglycerides [7].

The propensity to preferentially accumulate visceral fat in energy intake excess is highly variable from one individual to another [6]. Although some aspects may be related to a higher concentration of VAT, such as age, male gender, white color, inappropriate lifestyle (high intake of saturated fat, physical inactivity, smoking, alcohol consumption) and genetic influence, their determinants have not been sufficiently investigated [4-11]. There are still important gaps in the profile composition of subjects with a higher risk of visceral obesity. Therefore, the aim of this study was to determine the factors associated with the concentration of visceral and subcutaneous fat.

\section{Methods}

Data derive from case series study with exploratory analysis developed in a nutrition clinic of a public university hospital, a reference in cardiology, in the Brazilian northeast. It involved overweight individuals from both sexes and with $\geq 20$ years of age. In this clinic, patients are predominantly individuals with chronic diseases such as obesity, hypertension, diabetes mellitus, metabolic syndromes and dyslipidemia. The sample size was calculated using as reference a standard deviation (s) of $123.5 \mathrm{~cm}^{2}$ for the VAT area with an error margin of $6 \%\left(\mathrm{~d}=23.8 \mathrm{~cm}^{2}\right)$ and a reliability of $95 \%(\mathrm{z}=1.96)$. Using the formula $\mathrm{n}=\left[\left(\mathrm{z}^{2} \times \mathrm{s}^{2}\right) / \mathrm{d}^{2}\right]$, the minimum sample size was 104 individuals. In order to correct eventual losses, the sample " $n$ " was fixed at $10 \%[100 /$ (100-90)], totaling 116 individuals. The sample consisted of voluntary participation of patients during their first consultation. Individuals with ascites, recent abdominal surgery, pregnant women and women who had children up to 6 months before the screening were excluded. Individuals with physical disabilities (amputation of limbs) were also

*Corresponding author: Claudia Porto Sabino Pinho, university of Federal de Pernambuco, Nutricao,Recife, PE, Brazil, Tel: +55 8199635 6615; E-mail: claudiasabinopinho@hotmail.com

Received October 30, 2017; Accepted November 13, 2017; Published November 20, 2017

Citation: Pinho CPS, Diniz AS, de Arruda IKG, Leão APD, de Albuquerque EC, et al. (2017) Factors Associated With the Concentration of Visceral and Subcutaneous Fat. Health Care Current Reviews 5: 214. doi: 10.4172/2375-4273.1000214

Copyright: (C) 2017 Pinho CPS, et al. This is an open-access article distributed under the terms of the Creative Commons Attribution License, which permits unrestricted use, distribution, and reproduction in any medium, provided the original author and source are credited. 
considered ineligible for preventing anthropometric measurements. Overweight was established based on the body mass index (BMI) as $\geq 25$ $\mathrm{kg} / \mathrm{m}^{2}$ for adults and $\geq 27 \mathrm{~kg} / \mathrm{m}^{2}$ for seniors $[12,13]$. VAT and SAT were assessed by computed tomography (CT) scan using a Philips Brilliance CT-10 slice tomograph (VMI Indústria e Comércio Ltda, Lagoa Santa, MG, Brazil). The examination was conducted in patients with a fourhour fasting in the supine position. The tomographic cut was obtained with CT radiographic parameters of $140 \mathrm{kV}$ and $45 \mathrm{~mA}$ at the L4 level, with a thickness of $10 \mathrm{~mm}$. The total abdominal fat area and the visceral fat area were manually outlined with a free cursor contouring of each region. The entire surface of the skin was excluded from the area outlined. The VAT area was determined considering as limits the inner edges of the rectus abdominis, internal oblique and square lumbar muscles, excluding the vertebral body and including retroperitoneal, mesenteric and omental fat. The subcutaneous fat area was calculated by subtracting the VAT from the total fat area. All fat areas were described in $\mathrm{cm}^{2}$. For the identification of the adipose tissue, density values of -50 and -250 Hounsfield units were used $[14,15]$. Among the potential association variables, socioeconomic and demographic factors (age, gender, race, education and socioeconomic status), clinical factors (diabetes mellitus and systemic arterial hypertension) and behavioral variables (smoking, alcohol consumption, physical activity and food consumption) were considered.

The race was self-defined by the respondent as white, brown or black [16]. For analysis purposes, the dichotomized responses white and non-white were considered. Education was defined as total (complete) years of study. In determining the socioeconomic status, the "Brazilian Economic Classification Criteria" were employed, established by the Brazilian Association of Anthropology and the Brazilian Association of Research Companies [17]. This instrument uses a scale that assigns scores to the number of household items owned and to the level of education of the family head, classifying the population in the economic classes A1, A2, B1, B2, C1, C2, D and E, in descending order, respectively higher purchasing power and low purchase power. After the classification, the economic classification was dichotomized into subclasses: high economic class (A1, A2 and B1) and low economic class (B2, C1, C2, D and E). With regard to smoking, the following categories were considered: smoker (individual who reported smoking), non-smoker (individual who reported never having smoked) and former smoker (individual who reported smoking at some point in life, but not smoking at the time of the interview). For purposes of analysis, the dichotomized response "smoker" and "nonsmoker" was considered. For the variable alcohol consumption, the consumption of alcohol 30 days prior to the interview was evaluated, being the dichotomous answer yes or no. To determine the level of physical activity, the International Physical Activity Questionnaire (IPAQ), 2001, was used in its short version, which takes into account four dimensions of physical activity: leisure, household activities, occupational activities and transport activities [18]. A score for physical activity in minutes per week was designed by summing the minutes spent on the activities. A score below $150 \mathrm{~min} /$ week was the cutoff point used to classify individuals as insufficiently active or sedentary.

Food intake was assessed with a qualitative food frequency questionnaire (FFQ) proposed by Furlan-Viebig and Pastor-Valero [19]. It was validated for the study of the relation between diet and noncommunicable chronic diseases. It contains 98 items and four frequency categories (daily, weekly, monthly and "rarely/never"). Data related to intake were obtained by trained interviewers. The analysis of the FFQ was based on the methodology proposed by Fornés et al. [20], in which the general calculation of the intake frequency is converted into scores.
The referred proposal adopts as reference a daily intake equivalent to 30 days of the month (monthly intake). A weight is assigned to each frequency category. The weights of the intake frequencies were measured according to the following equation:

Weight $=(1 / 30) \times(a)$

Where, $a$ corresponds to the number of times the food was consumed during the month

Thus, a consumption frequency score was assigned to each food. Then, the score of each item was grouped into 6 groups: group 1 consisted of milk and dairy-derived food; group 2 was fatty and processed meats (meats with fat, poultry with skin, guts and sausage);group 3washighfiber foods, considered as preventing cardiovascular diseases and excessive weight gain (legumes, fruits and vegetables); group 4 was foods rich in simple carbohydrates (cake, biscuit, bread, sugar and soft drinks); group 5 consisted of alcoholic beverages; and group 6 was oils and fats (oils, butter and margarine).

The study protocol was guided by the ethical standards for research involving human subjects of the Resolution no. 466/12 of the National Health Council and was submitted to the Ethics and Research Committee on Human Beings of the University of Pernambuco (UPE), approved under protocol no. 271.400/2013. Individuals were informed of the research objectives and of the methods adopted. Upon their agreement, they signed an informed consent. Data were analyzed using the Statistical Package for Social Sciences (SPSS) version 13.0 (SPSS Inc., Chicago, IL, USA). The continuous variables were tested for normal distribution using the Kolmogorov-Smirnov test. When they had a normal distribution, they were described as means and standard deviation. Food intake scores, because they are ordinal variables, were described as medians and interquartile ranges. In the description of proportions, an approximation of binomial distribution to normal distribution was performed with a $95 \%$ confidence interval. The Student $\mathrm{t}$ test for independent samples was used to compare VAT and SAT means according to independent variables. Proportions were compared by Pearson's chi square test. The Mann-Whitney $U$ test was used to compare medians. The Spearman correlation test was used to analyze the correlation between the scores of food intake and VAT and SAT. A stepwise multiple linear regressions was used to investigate the relation between VAT and SAT (response variables) and independent variables. A Backward regression analysis was adopted for the modeling. The models in which the variables showed a VIF (variance inflation factor) $\leq 3.0$ were considered. Statistical significance was established when $\mathrm{p}<0.05$.

\section{Results}

116 individuals were interviewed and, after discarding losses due to refusal and information inconsistency, 109 individuals formed the final sample. The mean age was $50.3( \pm 12.2)$ years, with a higher proportion of women $\left(74.3 \%, \mathrm{CI}_{95 \%}: 65.0-82.2\right)$. There was no statistical difference regarding the variables age, BMI and prevalence of $\mathrm{DM}$ and $\mathrm{SAH}$ between genders $(p>0.05)$. Men had a higher absolute value of VAT $(\mathrm{p}<0.001)$ when compared to women. The VAT volume corresponded to $43.2 \%$ of the abdominal fat in males, a value higher than that found for women $(32.7 \% ; \mathrm{p}<0.001)$, who appear to be more prone to subcutaneous fat accumulation $(\mathrm{p}<0.001)$ (Table 1$)$. Men showed a higher consumption of fatty and processed meats $(\mathrm{p}=0.038)$ and alcohol $(\mathrm{p}=0.012)$ compared to women (Table 2$)$. In the univariate analysis, the highest concentration of VAT was found for hypertensive $(\mathrm{p}=0.008)$, diabetic $(\mathrm{p}=0.038)$ and obese $(\mathrm{p}=0.014)$ male patients. Regarding SAT, 
Citation: Pinho CPS, Diniz AS, de Arruda IKG, Leão APD, de Albuquerque EC, et al. (2017) Factors Associated With the Concentration of Visceral and Subcutaneous Fat. Health Care Current Reviews 5: 214. doi: 10.4172/2375-4273.1000214

Page 3 of 8

\begin{tabular}{|c|c|c|c|}
\hline Variables & $\begin{array}{l}\text { Males } \\
(n=28)\end{array}$ & $\begin{array}{c}\text { Females } \\
(n=81)\end{array}$ & p-value \\
\hline Idade, years (mean/SD) & $49.9( \pm 13.7)$ & $50.5( \pm 11.8)$ & $0.817^{\star}$ \\
\hline Hipertensão Arterial $\left(\%, \mathrm{Cl}_{95 \%}\right)$ & $67.9(47.6-84.1)$ & $59.3(47.8-70.0)$ & $0.420^{\S}$ \\
\hline Diabetes Mellitus $\left(\%, \mathrm{Cl}_{95 \%}\right)$ & $25.0(10.7-44.9)$ & $21.0(12.7-31.5)$ & $0.659 \S$ \\
\hline $\mathrm{IMC}, \mathrm{kg} / \mathrm{m}^{2}$ (mean/SD) & $33.1( \pm 4.9)$ & $33.5( \pm 5.3)$ & $0.715^{*}$ \\
\hline $\operatorname{TAV}\left(\mathrm{cm}^{2}\right)$ & $378.9( \pm 118.7)$ & $258.6( \pm 75.4)$ & $<0.001^{*}$ \\
\hline TAS $\left(\mathrm{cm}^{2}\right)$ & $506.3( \pm 162.2)$ & $540.9( \pm 145.6)$ & $0.294^{*}$ \\
\hline$\% \operatorname{TAV}($ mean/SD) & $43.2( \pm 10.3)$ & $32.7( \pm 8.3)$ & $<0.001^{*}$ \\
\hline$\%$ TAS (mean/SD) & $57.1( \pm 10.2)$ & $66.9( \pm 8.5)$ & $<0.001^{\star}$ \\
\hline
\end{tabular}

Student $t$ Test for independent samples

§Pearson Chi Square

SD: Standard Deviation; CI 95\%: Confidence Interval of 95\%; BMI: Body Mass Index; VAT: Visceral Adipose Tissue; SAT: Subcutaneous Adipose Tissue; \%VAT: Proportion of Visceral Fat in Relation to the Concentration of Total Abdominal Fat; \%SAT: Proportion of Subcutaneous Fat in Relation to the Concentration of Total Abdominal Fat

Table 1: Characteristics of the sample, stratified by sex $(n=109)$.

\begin{tabular}{|l|c|c|}
\hline Food group & $\begin{array}{c}\text { Males } \\
(\mathbf{n = 2 8 )}\end{array}$ & $\begin{array}{c}\text { Females } \\
(\mathbf{n = 8 1})\end{array}$ \\
\hline Milk and dairy-derived food & $1.17(0.80-2.30)$ & $1.27(0.80-2.73)$ \\
\hline Fatty and processed meats & $1.03(0.37-1.87)$ & $0.67(0.23-1.20)$ \\
\hline Protective foods & $2.73(1.60-3.90)$ & $2.90(1.96-3.93)$ \\
\hline Simple carbohydrates & $5.70(3.69-7.10)$ & $4.67(3.57-7.47)$ \\
\hline Alcohol & $0.00(0.00-0.20)$ & 0.361 \\
\hline Oils and fats & $2.00(0.93-3.00)$ & $0.00(0.00-0.03)$ \\
\hline
\end{tabular}

*Mann-Whitney U test

Table 2: Comparative analysis of the scores of consumption of food and alcohol in overweight adults, according to sex.

a higher concentration was observed in obese $(\mathrm{p}=0.027)$ and smoker $(\mathrm{p}<0.001)$ patients. An increased concentration of VAT was identified in women with SAH $(\mathrm{p}=0.003)$ and DM $(\mathrm{p}=0.022)$. SAT had higher averages in adult $(\mathrm{p}=0.016)$, Caucasian $(\mathrm{p}=0.049)$ and obese $(\mathrm{p}<0.001)$ women (Table 3). A correlation between dietary factors and VAT was not identified. The volume of SAT was positively correlated with the intake of protective food in males (Table 4). In the multivariate analysis, the presence of SAH, a higher BMI and a lower intake of protective food was associated with VAT in males, whose adjusted coefficient of determination was $46.4 \%$. The adjusted determination coefficient of the model for SAT was much higher (88.6\%).SAH, increased education time (in years), high BMI and low consumption of oils and fats were significantly associated with subcutaneous fat. Regarding women, age (older), SAH, an increased BMI and alcohol consumption were associated with VAT (adjusted $\mathrm{R}^{2}=17.6 \%$ ) and increased BMI, increased education time, high intake of fatty and processed meats and low simple carbohydrates consumption were association with SAT after the adjustment of the confounding variables (adjusted $\mathrm{R}^{2}=69.3 \%$ ) (Table 5).

\section{Discussion}

The highest concentration of visceral fat observed in males was also reported by other authors [6,8,21]. Kuk et al. [22] showed that, considering an equal waist circumference, men had a higher volume of visceral fat compared to women. Men and women are very different in terms of body fat distribution and such substantial differences are almost unique to humans. The sexual dimorphism of fat distribution patterns in humans is regulated by hormonal differences. Although the role that each hormone plays in the modulation of body fat is not completely understood, some evidence suggests that estrogens have a significant influence on the function of the adipose tissue and may be an important determinant in the differences of composition and standardization of body fat [6]. This hypothesis is supported by studies which indicate that the reduction in estrogen levels after menopause is associated with increased adiposity and fat accumulation in the visceral compartment
$[23,24]$. Furthermore, a study with transgenders demonstrated that female-men treated with estrogens showed a significant increase in the subcutaneous fat deposition without influence on the visceral fat compartment $[25,26]$. On the other hand, male-to-female transsexuals treated with intramuscular injections of testosterone showed progressive changes in fat distribution, from a gynecoid standard to android, over three years $[25,26]$. The greater tendency to accumulate VAT in males seems to be an essential factor to explain why obesity is more dangerous for men than women [6]. Although an older age has not been associated with a higher concentration of visceral fat based on the results of our investigation, it is known that changes occur in the body composition with age, so that the fat-free mass decreases and the fat mass generally increases, being stored in intra-abdominal and intramuscular anatomical sites rather than subcutaneously, as usually occurs in young adults [27]. Therefore, VAT greatly accumulates with age. This is an important predictor variable of its accumulation [4]. One study showed an annual increase of $2.36 \mathrm{~cm}^{2}$ in VAT in non-obese women [28]. This increase in visceral adiposity paripassu with the progression of age implies a deterioration of the metabolic and hemodynamic profile [6].

There was no significant difference in the concentration of VAT in relation to race for both genders. However, some studies have described an increased volume of visceral fat considering a similar level of body fatness in Caucasians compared to African-Americans [29,30]. Marked differences in the regional distribution of the adipose tissue depending on race have been reported worldwide. For a given weight gain, some populations would have a higher tendency to accumulate SAT, while other populations would more likely accumulate adipose tissue in the visceral cavity [6]. Asians, for example, would be more prone to accumulate visceral fat, despite the lower amount of body fat compared to individuals from other ethnic backgrounds $[31,32]$. An increased risk of morbidity and mortality related to obesity in Asians compared to Caucasians has also been identified for the same 
Citation: Pinho CPS, Diniz AS, de Arruda IKG, Leão APD, de Albuquerque EC, et al. (2017) Factors Associated With the Concentration of Visceral and Subcutaneous Fat. Health Care Current Reviews 5: 214. doi: 10.4172/2375-4273.1000214

Page 4 of 8

\begin{tabular}{|c|c|c|c|c|c|c|}
\hline \multirow{2}{*}{ Variables } & \multicolumn{3}{|c|}{ Males $(n=28)$} & \multicolumn{3}{|c|}{ Females $(n=81)$} \\
\hline & $\mathbf{n}$ & VAT & SAT & $\mathbf{n}$ & VAT & SAT \\
\hline \multicolumn{7}{|l|}{ Age group } \\
\hline Adult & 21 & $361.2( \pm 109.7)$ & $528.0( \pm 173.0)$ & 62 & $251.5( \pm 77.7)$ & $557.7( \pm 155.4)$ \\
\hline Elderly & 7 & $432.2( \pm 137.3)$ & $441.2( \pm 109.7)$ & 19 & $281.8( \pm 63.7)$ & $486.4( \pm 91.1)$ \\
\hline p-value ${ }^{*}$ & & 0.175 & 0.227 & & 0.125 & 0.016 \\
\hline \multicolumn{7}{|l|}{ Race } \\
\hline White & 11 & $383.7( \pm 122.7)$ & $467.8( \pm 147.8)$ & 31 & $256.2( \pm 60.3)$ & $581.4( \pm 146.5)$ \\
\hline Non White & 17 & $374.8( \pm 120.0)$ & $531.1( \pm 170.5)$ & 47 & $260.1( \pm 83.9)$ & $515.9( \pm 140.7)$ \\
\hline$p$-value ${ }^{*}$ & & 0.868 & 0.322 & & 0.824 & 0.049 \\
\hline \multicolumn{7}{|l|}{ Escolaridade } \\
\hline$\leq 9$ years & 7 & $402.9( \pm 125.2)$ & $505.1( \pm 156.5)$ & 25 & $270.4( \pm 80.4)$ & $505.0( \pm 156.3)$ \\
\hline$>9$ years & 21 & $371.0( \pm 118.5)$ & $506.6( \pm 167.8)$ & 56 & $253.3( \pm 73.1)$ & $557.0( \pm 139.0)$ \\
\hline$p$-value* & & 0.548 & 0.983 & & 0.349 & 0.139 \\
\hline \multicolumn{7}{|l|}{ Social class ${ }^{\S}$} \\
\hline Upper & 6 & $412.3( \pm 100.3)$ & $532.7( \pm 121.6)$ & 9 & $233.0( \pm 56.1)$ & $514.7( \pm 113.1)$ \\
\hline Low & 22 & $369.8( \pm 123.7)$ & $499.0( \pm 173.3)$ & 71 & $262.7( \pm 77.3)$ & $545.6( \pm 150.1)$ \\
\hline$p$-value* & & 0.448 & 0.660 & & 0.269 & 0.554 \\
\hline \multicolumn{7}{|l|}{ SAH } \\
\hline No & 9 & $295.7( \pm 76.1)$ & $563.3( \pm 199.1)$ & 33 & $229.1( \pm 65.2)$ & $560.7( \pm 153.9)$ \\
\hline Yes & 19 & $418.4( \pm 116.0)$ & $479.2( \pm 139.4)$ & 48 & $278.8( \pm 75.8)$ & $527.4( \pm 139.6)$ \\
\hline$p$-value ${ }^{*}$ & & 0.008 & 0.206 & & 0.003 & 0.315 \\
\hline \multicolumn{7}{|l|}{ DM } \\
\hline No & 21 & $352.4( \pm 98.3)$ & $521.1( \pm 177.2)$ & 64 & $248.8( \pm 68.2)$ & $531.9( \pm 145.4)$ \\
\hline Yes & 7 & $458.6( \pm 145.9)$ & $461.9( \pm 103.2)$ & 17 & $295.5( \pm 90.9)$ & $575.0( \pm 145.5)$ \\
\hline p-value* & & 0.038 & 0.413 & & 0.022 & 0.281 \\
\hline \multicolumn{7}{|l|}{ BMI } \\
\hline Overweight & 7 & $278.9( \pm 52.9)$ & $390.5( \pm 56.6)$ & 23 & $232.6( \pm 53.8)$ & $420.1( \pm 79.2)$ \\
\hline Obesity & 21 & $411.0( \pm 118.2)$ & $550.0(161.8)$ & 58 & $269.0( \pm 80.8)$ & $591.1(134.7)$ \\
\hline$p$-value* & & 0.014 & 0.027 & & 0.054 & $<0.001$ \\
\hline \multicolumn{7}{|l|}{ Tabagismo } \\
\hline Smoker & 5 & $450.9( \pm 17.7)$ & $769.1( \pm 180.4)$ & 7 & $276.2( \pm 70.1)$ & $521.4( \pm 118.2)$ \\
\hline Non smoker & 23 & $380.8( \pm 122.0)$ & $460.3( \pm 121.9)$ & 74 & $254.4( \pm 72.7)$ & $543.4( \pm 149.4)$ \\
\hline$p$-value* & & 0.339 & $<0.001$ & & 0.519 & 0.748 \\
\hline \multicolumn{7}{|c|}{ Alcohol conumption } \\
\hline Yes & 13 & $386.3( \pm 110.2)$ & $508.1( \pm 103.9)$ & 60 & $262.7( \pm 71.7)$ & $537.5( \pm 144.8)$ \\
\hline No & 15 & $366.8( \pm 131.9)$ & $488.2( \pm 200.8)$ & 21 & $234.2( \pm 71.5)$ & $556.5( \pm 157.4)$ \\
\hline$p$-value* & & 0.681 & 0.747 & & 0.136 & 0.626 \\
\hline \multicolumn{7}{|l|}{ Physical activity } \\
\hline$<150 \mathrm{~min} /$ week & 20 & $374.6( \pm 104.4)$ & $527.3( \pm 108.9)$ & 46 & $269.9( \pm 70.2)$ & $543.9( \pm 135.3)$ \\
\hline$\geq 150 \mathrm{~min} /$ week & 8 & $415.5( \pm 149.9)$ & $443.3( \pm 92.5)$ & 35 & $243.8( \pm 80.3)$ & $537.0( \pm 160.1)$ \\
\hline$p$-value ${ }^{*}$ & & 0.432 & 0.255 & & 0.124 & 0.834 \\
\hline
\end{tabular}

"t-Student test for independent measures

Adult: $<60$ years; Elderly: $\geq 60$ years

SAH: Systemic Arterial Hypertension; DM: Diabetes Mellitus; BMI: Body Mass Index

Overweight: BMl<25 kg/m² for adults and $<27 \mathrm{~kg} / \mathrm{m}^{2}$ for the elderly; Obesity: BMI $\geq 30 \mathrm{~kg} / \mathrm{m}^{2}$.

$\S$ Social class defined according to the Brazilian Economic Classification criteria

Table 3: Factors associated with the concentration of visceral adipose tissue (VAT) and subcutaneous adipose tissue (SAT) in individuals with overweight, stratified according to sex.

BMI and waist circumference. This can be attributed to a greater predisposition to accumulate VAT [33]. Several hypotheses have been postulated to explain the physiological mechanisms of fat distribution differences related to ethnicity, being more plausible the proposals that attribute these various racial characteristics to genetic and epigenetic programming [32]. In general, a higher propensity to accumulate VAT shown by some populations may contribute to higher rates of diabetes mellitus type 2 and cardiovascular diseases [6]. It should be noted that the Brazilian population is characterized by a great miscegenation with a complex definition. The methodology used in our research was the self-definition of race by the respondent and one should consider the possibility of assessment error [16]. Many studies have shown a relation between excess weight and socioeconomic variables. However, no result from the analyses demonstrates the influence of these variables in visceral and subcutaneous fat stores. Therefore, the direct association between education and SAT concentration observed in our study for both genders, in the adjusted analysis, is a fact that needs more evidence to enable its discussion given the analytical complexity of explaining how social aspects may influence biological questions. The classic compartment of storage of excess calories is the SAT. Nonetheless, when the lipid storage capacity is exceeded, the store is diverted to other compartments outside the subcutaneous tissue, such as VAT, 
Citation: Pinho CPS, Diniz AS, de Arruda IKG, Leão APD, de Albuquerque EC, et al. (2017) Factors Associated With the Concentration of Visceral and Subcutaneous Fat. Health Care Current Reviews 5: 214. doi: 10.4172/2375-4273.1000214

Page 5 of 8

\begin{tabular}{|c|c|c|c|c|}
\hline \multirow{3}{*}{ Food group } & \multicolumn{4}{|c|}{ Males ( $n=28)$} \\
\hline & \multicolumn{2}{|c|}{ VAT } & \multicolumn{2}{|c|}{ SAT } \\
\hline & $r$ & $p$-value & $r$ & p-value \\
\hline Milk and dairy products & -0.084 & 0.677 & 0.138 & 0.491 \\
\hline Fat and processed meats & 0.275 & 0.164 & 0.106 & 0.599 \\
\hline Protective foods & 0.002 & 0.994 & 0.383 & 0.049 \\
\hline Simple carbohydrates & 0.095 & 0.639 & 0.028 & 0.889 \\
\hline Alcohol & -0.082 & 0.683 & -0.125 & 0.534 \\
\hline Oils and fats & 0.103 & 0.608 & 0.074 & 0.715 \\
\hline \multirow{3}{*}{ Food group } & \multicolumn{4}{|c|}{ Females $(n=81)$} \\
\hline & \multicolumn{2}{|c|}{ VAT } & \multicolumn{2}{|c|}{ SAT } \\
\hline & $\mathbf{r}$ & $p$-value & $r$ & p-value \\
\hline Milk and dairy-derived food & 0.016 & 0.887 & 0.130 & 0.254 \\
\hline Fatty and processed meats & -0.039 & 0.731 & 0.097 & 0.394 \\
\hline Protective foods & 0.113 & 0.326 & 0.106 & 0.353 \\
\hline Simple carbohydrates & -0.056 & 0.625 & -0.154 & 0.175 \\
\hline Alcohol & -0.211 & 0.062 & 0.074 & 0.517 \\
\hline Oils and fats & 0.138 & 0.226 & 0.912 & 0.090 \\
\hline
\end{tabular}

Table 4: Spearman correlation between the scores of consumption of food and alcohol with the visceral adipose tissue (VAT) and the subcutaneous adipose tissue (SAT) in overweight individuals, according to sex.

\begin{tabular}{|c|c|c|c|c|c|c|c|}
\hline \multirow[b]{3}{*}{ Variables } & \multicolumn{7}{|c|}{ Males $(n=28)$} \\
\hline & \multicolumn{7}{|c|}{ Visceral adipose tissue } \\
\hline & Coeficiente & Erro Padrão & 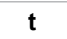 & p-value & VIF & $\mathbf{R}^{2}$ & $\mathbf{R}^{2}$ Adjusted \\
\hline Constante & -57.5 & 117.3 & -0.4 & 0.629 & & \multirow{2}{*}{53.6} & \multirow{2}{*}{46.6} \\
\hline HAS & 151.7 & 38.5 & 3.9 & 0.001 & 1.2 & & \\
\hline IMC $\left(\mathbf{k g} / \mathbf{m}^{2}\right)$ & 12.7 & 3.7 & 3.5 & 0.002 & 1.2 & & \\
\hline Alimentos protetores* & -30.6 & 14.7 & -2.1 & 0.050 & 1.4 & & \\
\hline \multirow[b]{2}{*}{ Variables } & \multicolumn{7}{|c|}{ Subcutaneous adipose tissue } \\
\hline & Coeficiente & Erro Padrão & $\mathbf{t}$ & p-value & VIF & $\mathbf{R}^{2}$ & $\mathbf{R}^{2}$ Adjusted \\
\hline Constante & -488.1 & 89.7 & -5.4 & $<0.001$ & & \multirow{4}{*}{90.6} & \multirow{4}{*}{88.6} \\
\hline IMC & 29.2 & 2.2 & 12.9 & $<0.001$ & 1.1 & & \\
\hline HAS & -67.8 & 23.7 & -2.9 & 0.010 & 1.1 & & \\
\hline Anos de estudo & 11.1 & 3.2 & 3.5 & 0.002 & 1.1 & & \\
\hline \multirow[t]{2}{*}{ Óleos e gorduras } & -21.4 & 10.5 & -2.0 & 0.055 & 1.1 & & \\
\hline & \multicolumn{7}{|c|}{ Females $(n=81)$} \\
\hline & \multicolumn{7}{|c|}{ Visceral adipose tissue } \\
\hline Variables & Coefficient & Standard Error & $t$ & $p$-value & VIF & $\mathbf{R}^{2}$ & $\mathbf{R}^{2}$ Adjusted \\
\hline Constant & 60.8 & 63.1 & 1.8 & 0.076 & & \multirow{4}{*}{22.1} & \multirow{4}{*}{17.6} \\
\hline Age & 1.4 & 0.8 & 1.9 & 0.062 & 1.0 & & \\
\hline SAH & 32.0 & 17.5 & 1.8 & 0.072 & 1.3 & & \\
\hline BMI & 3.3 & 1.5 & 2.2 & 0.028 & 1.0 & & \\
\hline Alcohol $^{\star}$ & -57.9 & 31.1 & -1.9 & 0.067 & 1.0 & & \\
\hline \multirow[b]{2}{*}{ Variables } & \multicolumn{7}{|c|}{ Subcutaneous adipose tissue } \\
\hline & Coefficient & Standard Error & $\mathbf{t}$ & p-value & VIF & $\mathbf{R}^{2}$ & $\mathbf{R}^{2}$ Adjusted \\
\hline Constant & -245.0 & 68.5 & -3.6 & 0.001 & & \multirow{5}{*}{71.0} & \multirow{5}{*}{69.3} \\
\hline BMI & 21.6 & 1.8 & 11.9 & $<0.001$ & 1.0 & & \\
\hline Years of study & 6.7 & 2.3 & 2.9 & 0.006 & 1.0 & & \\
\hline Fat and processed meats ${ }^{*}$ & 36.1 & 17.7 & 2.0 & 0.045 & 1.2 & & \\
\hline Simple carbohydrates ${ }^{*}$ & -5.9 & 3.5 & -1.7 & 0.096 & 1.2 & & \\
\hline
\end{tabular}

*Consumption score, as proposed by Fornes et al. [20]

BMI: Body Mass Index; SAH: Systemic Arterial Hypertension; DM: Diabetes Mellitus; VIF: Variance Inflation Factor

For the regression, continuous variables (age, BMI, education in years of study, minutes of physical activity per week, food consumption score (simple carbohydrates, fat and processed meats, milk and dairy products, oils and fats, protective foods and alcohol) and dummy variables (SAH, DM, race, social class and smoking) entered the models

Table 5: Multiple linear regressions of factors associated with the concentration of visceral adipose tissue (VAT) and subcutaneous adipose tissue (SAT) in individuals with overweight, stratified according to sex.

skeletal muscle and the liver, compromising their normal metabolic pathways and promoting unfavorable situations [34]. Some authors suggested that the SAT may have protective properties and that an absolute quantification of any deposit does not reflect its proportional distribution $[8,35,36]$. For example, a high volume of VAT or SAT may reflect both a high total abdominal fat mass and propensity to store 
visceral or subcutaneous fat. Thus, to separate the absolute amount of fat from a greater predisposition to store viscerally or subcutaneously, the use of the VAT/SAT ratio has been proposed as a relative metric of abdominal fat composition [36]. Hence, higher levels of subcutaneous fat in individuals with higher education levels may imply that these individuals would accumulate more subcutaneous fat than visceral fat. However, this finding is only an inference, as this analysis was not performed. High levels of visceral fat were observed in men and women with arterial hypertension, and some mechanisms are described to explain this relation. In addition to the changes in the components of the renin-angiotensin-aldosterone system observed in obesity and in the mechanisms related to insulin resistance, evidence indicates that the fat deposition in the renal sinus may cause structural changes to the kidneys, leading eventually to the loss of the nephron function [5,37]. The highest concentration of visceral fat in diabetic men and women is a result consistent with previously published data connecting excess VAT to glucose homeostasis and plasmatic insulin disturbances [38]. A prospective study conducted by Boyko et al. [39] found, in JapaneseAmericans followed for 6-10 years, that excess visceral adiposity preceded the development of type $2 \mathrm{DM}$, even after controlling confounding variables such as basal levels of insulin and glucose, total adiposity and family history of diabetes. Another study demonstrated that obese men and women with low levels of VAT had a normal glucose tolerance, similar to lean controls [40]. This association between excess of visceral fat and deterioration of the glucose metabolism is related to the direct supply of free fatty acids and inflammatory adipokines to the liver, secreted by the visceral adipocytes [5-7].

The combined effect of these metabolically active molecules determines insulin sensitivity and the impact on the endothelial function. Free fatty acids inhibit the secretion of insulin by pancreatic cells and limit the uptake of insulin-induced glucose probably by decreasing signaling and transduction mechanisms [5,7]. The highest concentration of visceral and subcutaneous adiposity in obese men and women is an expected finding. Although it is known that the BMI does not reflect the distribution of fat and does not establish the composition of abdominal fat, the deposits of subcutaneous and visceral abdominal fat increase with increases in weight and BMI [4]. In addition, BMI was associated with VAT and SAT, even after controlling confounding variables. Although the BMI is a predictor of the percentage of fat and not of its distribution, some studies investigated whether this parameter would associate with VAT. Even though the performance of BMI as a predictor variable for VAT was lower when compared to abdominal obesity markers, a correlation between this parameter and the amount of visceral fat was observed [41,42]. Behavioral habits have also been linked to visceral fat accumulation $[6,11]$. One study found a lower average VAT and SAT in subjects that had a healthier lifestyle [11]. Despite the considerable amount of data in the literature showing that smokers have a lower BMI compared with former smokers and non-smokers due to the action of nicotine in increased metabolic rate and appetite suppression, evidence indicates that smokers have a higher volume of VAT $[11,43,44]$. Although this association was not observed in our study, the underlying principles that relate smoking to a greater concentration of visceral fat are not entirely clear. It is possible that smoking affects lipid store in the visceral compartment by reducing the bioavailability of endogenous estrogens and increasing the production of adrenal androgens in women and men, contributing to a greater visceral adiposity [45]. A work studying the association between lifestyle variables and volume of VAT and SAT in 2,296 individuals participating in the Framingham study identified higher levels of VAT in smoking men and women $\left(218.8 \pm 66 \mathrm{~cm}^{3}\right.$ and $139.3 \pm 59 \mathrm{~cm}^{3}$, respectively) compared to non-smokers $\left(208.6 \pm 3 \mathrm{~cm}^{3}\right.$ and $125.0 \pm$ $30 \mathrm{~cm}^{3}$, respectively). The volume of subcutaneous fat, however, was higher in former smokers compared to current smokers and those who never smoked [11] The tendency to accumulate visceral fat in women who reported high alcohol consumption $(p=0.067)$ can be explained by the fact that the habitual consumption of alcoholic drinks leads to liver fat accumulation, resulting in insulin resistance and subsequent weight gain [46]. Some authors have also reported an association between the volume of visceral fat and consumption of alcohol in men and women $[11,44]$.

It is difficult to quantify the effects of alcohol consumption on the concentration of visceral and subcutaneous fat, especially due to a great methodological variation found in the literature regarding the analysis of the frequency and amount of alcohol consumed. It should also be noted that the methodological selection for the evaluation of alcohol consumption in the population studied (dichotomized into "consume" and "do not consume" and evaluated based on the consumption frequency score) is possibly a limiting factor for the analysis, mainly because these definitions do not reflect the amount of ethanol ingested regularly. A sedentary lifestyle causes in the individual a greater susceptibility to be in a positive energy imbalance. However, whether or not the lack of physical activity increases the susceptibility to as elective deposition of fat in the visceral compartment is not yet fully established [6]. Our study found no difference in average VAT and SAT when sedentary and sufficiently active individuals were compared. Some evidence, however, suggest that physical activity could lead to a substantial reduction of the visceral adiposity concomitantly to weight loss or even without weight loss [47]. Prospective studies evaluating the effects of sedentarism on the abdominal adipose tissue compartments are needed to clarify this possible association.

Our research revealed an inverse association between the intake of protective food and the concentration of visceral fat in men. Thus, the increased consumption of high-fiber foods seems to protect against the accumulation of the most deleterious fraction of abdominal fat. Romaguerra et al. [10] showed that the diet glycemic index correlated directly with visceral adiposity, suggesting that a higher fiber intake (low-glycemic-index foods) stimulates satiety, leading to a lower energy intake. Furthermore, it is possible that the glycidic and postprandial insulin response affects the partitioning of nutrients, increasing the susceptibility to accumulation of visceral fat in comparison with subcutaneous fat. It has been postulated that some aspects of the diet may influence body fat distribution [10]. Nonetheless, most of the previous studies were based on abdominal circumference measurements. Few studies explored the role of dietary factors as predictors of visceral and subcutaneous adiposity. The higher consumption of fatty and processed meats (foods rich in saturated fat) was associated with subcutaneous fat in women, a result which does not corroborate other previously published data. Evidence from an experimental study in rats showed that a high saturated fat intake might predispose a preferential accumulation of visceral fat compared to other types of fat [48]. However, studies on fat distribution in animals are difficult to be extrapolated to humans. In humans, the relation between sexual dimorphism and body fat distribution is much more accentuated [6]. Another study identified that a diet consistent with healthy dietary guidelines was related to smaller volumes of VAT and SAT [11]. Notwithstanding, most of the studies that investigated the relation between dietary aspects and visceral and subcutaneous fat concentrations are cross-sectional and, therefore, limited in the analysis of cause and effect relations. Moreover, from the results obtained in our research, it was observed that different factors were included in the 
explanatory multivariate model of the concentration of VAT and SAT in men and women. It is thus possible to suggest that abdominal adiposity store is modulated by different factors between genders. In addition, the low regression coefficient of the multiple models accounting for the volume of visceral fat, especially among women, may indicate that other non-studied variables may be involved in determining visceral fat store. This is different from the multiple models for SAT, in which high adjusted regression coefficients were observed.

The cross-sectional design adopted in our study limits the analysis of causal relations among exposure variables (especially behavioral variables such as level of physical activity, alcohol consumption, smoking and eating habits) and the outcome (visceral and subcutaneous adiposity), which may cause possible reverse causalities among associations. Another limiting aspect was the small number of individuals evaluated and the heterogeneous distribution of the sample between the genders. Nonetheless, it is important to consider that the use of imaging to assess body composition is restricted when evaluating large groups due to the high cost of its use. Another methodological limitation of this study is that genetic aspects were not analyzed. They are important predictors of the composition and distribution of body fat. Some studies reported that genetic variants may be related to the preferential accumulation of visceral fat, and the absence of this variable in the model may have reduced its explanatory power in determining the volume of VAT [49,50]. In addition, the analysis of food consumption was performed using the FFQ, which reflects the qualitative aspects of diets, not considering the quantity. Therefore, it is salutary to develop further studies quantifying intake levels in order to clarify the role of nutrients in the modulation of abdominal fat store.

\section{Conclusion}

Aiming to describe and analyze the determinants of abdominal fat deposits, this study outlines an important characterization of the central adiposity issue and determines some risk factors, thus offering subsidies to new research contributions in this field of investigation. Some conclusions are well characterized: increased risk of a high concentration of visceral fat in diabetic, hypertensive male individuals and in those with an increased BMI. Other factors, distinct between genders, may also influence visceral fat store: lower fiber intake among men, and older age and alcohol consumption among women. Similarly, multiple factors determine the amount of subcutaneous fat: SAH, BMI, education level and dietary factors. It is still necessary to gather more evidence from different populations to define the profile of patients with a higher risk of visceral obesity. Prospective studies could be useful to describe more precisely how demographic, social and behavioral characteristics could affect intra-abdominal fat store.

\section{Conflicts of Interest}

None

\section{Transparency Declaration}

The lead author affirms that this manuscript is an honest, accurate and transparent account of the study being reported. The reporting of this work is compliant with CONSORT1/STROBE2/PRISMA3 guidelines. The lead author affirms that no important aspects of the study have been omitted and that any discrepancies from the study as planned have been explained.

\section{References}

1. Clinical guidelines on the identification, evaluation, and treatment of overweight and obesity in adults: The evidence report national institutes of health. Obes Res 6: 51S-209S.

2. Janssen I, Katzmarzyk PT, Ross R (2004) Waist circumference and not body mass index explains obesity-related health risk. Am J ClinNutr 79: 379-384.
3. Wang J (2003) Waist circumference: A simple, inexpensive and reliable tool that should be included as part of physical examinations in the doctor's office. Am J ClinNutr 78: 902-903

4. Wajchenberg BL (2000) Subcutaneous and visceral adipose tissue: Their relation to the metabolic syndrome. Endocr Rev 21: 679-738.

5. Ibrahim MM (2010) Subcutaneous and visceral adipose tissue: Structural and functional differences. Obesity Rev 11: 11-18.

6. Tchernof A, Després JP (2013) Pathophisiology of human visceral obesity: Na update. Physiol Rev 93: 359-404.

7. Jensen MD (2008) Role of body fat distribution and the metabolic complications of obesity. J Clin Endocrinol Metab 93: S57-S63.

8. Porter SA, Massaro JM, Hoffmann U (2009) Abdominal subcutaneous adipose tissue: A protective fat depot? Diabetes Care 32: 1068-1075.

9. Carroll JF, Chiapa AL, Rodriguez M (2008) Visceral fat, waist circumference and BMI: Impact of race/ethnicit. Obesity 16: 600-607.

10. Romaguerra D, Angquist L, Du H (2010) Dietary determinants of changes in waist circumference adjusted for body mass índex - A Proxy measured of visceral adiposity. Plos One 5: 1-7.

11. Molenaar EA, Massaro JM, Jacques PF (2009) Association of lifestyle factors with abdominal subcutaneous and visceral adiposity: The Framinghan Heart Study. Diabetes Care 32: 505-510.

12. Preventing and Managing the Global Epidemic. Technical Report Series no. 894. Geneva: World Health Organization Obesity.

13. Lipschitz DA (1994) Screening for nutritional status in the elderly 21: 55-67.

14. Borkan GA, Gerzof SG, Robbins AH (1982) Assessment of abdominal fat content by computed tomography. Am J Clin Nut 36: 172-177.

15. Rockall AG, Sohaib SA, Evans S (2003) Computed tomography assessment of fat distribution in male and female patients with Cushing's syndrome. Eur $\mathrm{J}$ Endoc 149: 561-567.

16. Maio MC, Monteiro S, Chor D (2005) Ethnicity/race in the Pró-Saúde Study: Comparative results of two methods of self-classification in Rio de Janeiro, Brazil. Cad Saúde Publica 21: 171-180.

17. http://www.abep.org/codigosguias/Criterio Brasil 2010.pdf

18. http://ipaq.ki.se/ipaq.htm

19. Furlan-Viebig R, Pastor-Valero M (2004) Development of a food frequency questionnaire to study diet and non-communicable diseases in adult population. Rev Saúde Publica 38: 581-584.

20. Fornes NS, Martins IS, Velasquez-Melendez G (2002) Food consumption scores and serum lipids levels in the population of São Paulo, Brazil. Rev Saúde Pública 36: 12-18.

21. Kim HI, Kim JT, Yu SH (2011) Gender differences in diagnostic values of visceral fat area and waist circumference for predicting metabolic syndrome in Koreans. J Korean Med Sci 26: 906-913.

22. Kuk JL, Lee S, Heymsfield SB (2005) Waisert circumference and abdominal adipose tissue distribution: Influence of age and sex. Am J Clin Nutr 81: 1330 1334.

23. Keller C, Larkey L, Distefano JK (2010) Perimenopausal obesity. J Womens Health 19: 987-996.

24. Lovejoy JC, Champagne CM, de Jonge $L$ (2008) Increased visceral fat and decreased energy expenditure during the menopausal transition. Int $\mathrm{J}$ Obes 32: 949-958.

25. Elbers JM, Asscheman H, Seidell JC (1999) Effects of sex steroid hormones on regional fat depots as assessed by magnetic resonance imaging in transsexuals. Am J Physiol Endocrinol Metab 276: E317-E25.

26. Elbers JM, Giltay EJ, Teerlink T (2003) Effects of sex steroids on components of the insulin resistance syndrome in transsexual subjects. Clin Endocrinol 58: 562-571.

27. Cervi A, Franceschini SMC, Priore SE (2005) Critical analysis of the use of the body mass índex for the elderly. Rev Nutr 18: 765-775.

28. Denino WF, Tchernof A, Dionne IJ (2001) Contribution of abdominal adiposity to age-related differences in insulin sensitivity and plasma lipids in healthy non obese women. Diabetes Care 24: 925-932. 
Citation: Pinho CPS, Diniz AS, de Arruda IKG, Leão APD, de Albuquerque EC, et al. (2017) Factors Associated With the Concentration of Visceral and Subcutaneous Fat. Health Care Current Reviews 5: 214. doi: 10.4172/2375-4273.1000214

29. Després JP, Couillard C, Cagnon J (2000) Race, visceral adipose tissue, plasma lipids and lipoprotein lípase activity in men and women: The health, risk factors, exercise training, genetics (HERITAGE) family study. Arterioscler Thromb Vasc Biol 20: 1932-1938.

30. Camhi SM, Bray GA, Bouchard C (2011) The relationship of waist circumference and BMI to visceral, subcutaneous, and total body fat: Sex and race differences. Obesity 19: 402-408

31. Kadowaki T, Sekikawa A, Murata K (2006) Japanese men have larger areas of visceral adipose tissue than Caucasian men in the same levels of waist circumference in a population-based study. Int J Obes 30: 1163-1165.

32. Misra A, Khurana L (2009) The metabolic syndrome in South Asians: Epidemiology, determinants, and prevention. Metab Syndr Relat Disord 7: 497514.

33. Misra A, Vikram NK, Gupta R (2006) Waist circumference cutoff points and action levels for Asian Indians for identification of abdominal obesity. Int J Obes (Lond) 30: 106-111.

34. Weiss R (2007) Fat distribution and storage: how much, where and how? Eur J Endocrinol 157: S39-S45.

35. Tran TT, Yamamoto Y, Gesta S (2008) Beneficial effects of subcutaneous fat transplantation on metabolism. Cell Metab 7: 410-420.

36. Kaess BM, Pedley A, Massaro JM (2012) The ratio of visceral to subcutaneous fat, a metric of body fat distribution, is a unique correlate of cardiometabolic risk. Diabetologia 55: 2622-2630.

37. Foster MC, Hwang SJ, Porter SA (2011) Fatty kidney, hypertension and chronic kidney disease: The Framingham Heart Study. Hypertension 58: 784-790.

38. Ross R, Aru J, Freeman J (2002) Abdominal adiposity and insulin resistance in obese men. Am J Physiol Endocrinol Metab 282: E657-E63.

39. Boyko EJ, Fujimoto WY, Leonetti DL (2000) Visceral adiposity and risk of type 2 diabetes: A prospective study among Japanese Americans. Diabetes Care 23: $465-471$
40. Després JP, Moorjani S, Lupien PJ (1990) Regional distribution of body fat plasma lipoproteins and cardiovascular disease. Arteriosclerosis 10: 497-511.

41. Kullberg J, von Below C, Lonn L (2007) Practical approach for estimation of subcutaneous and visceral adipose tissue. Clin Physiol Funct Imaging 27:148153.

42. Goel K, Grupta N, Misra A (2008) Predictive equations for body fat and abdominal fat with DXA and MRI as reference in Asian Indians. Obesity 16 $451-456$.

43. Mineur YS, Abizaid A, Rao Y (2011) Nicotine decreases food intake through activation of POMC neurons. Science 332: 1330-1332.

44. Komiya $\mathrm{H}$, Mori $\mathrm{Y}$, Yokose $\mathrm{T}$ (2006) Smoking as a risk factor for visceral fat accumulation in Japanese men. Tohoku J Exp Med 208: 123-132.

45. Toth MJ, Tchernoff A, Sites CK (2000) Effect of menopausal status on body composition and abdominal fat distribution. Int $\mathrm{J}$ Obesity Relat Metab Disord 24: $226-231$

46. Lazarus R, Sparrow D, Weiss S (1998) Temporal relations between obesity and insulin: Longitudinal data from the Normative Aging Study. Am J Epidemiol 147: $173-179$.

47. Ross R, Dagnone D, Jones PJ (2000) Reduction in obesity and related comorbid conditions after diet-induced weight loss or exercise-induced weight loss in men: A randomized, controlled trial. Ann Intern Med 133: 92-103.

48. Dorfman SE, Laurent D, Gounarides JS (2009) Metabolic implications of dietary trans fatty acids. Obesity 17: 1200-1207.

49. Bouchard L, Weisnagel SJ, Engert JC (2004) Human resistin gene polymorphism is associated with visceral obesity and fasting and oral glucose stimulated C-peptide in the Quebec Family Study. J Endocrinol Invest 27: 10031009 .

50. Pausova Z, Abrahamowicz M, Mahboubi A (2010) Functional variation in the androgen-receptor gene is associated with visceral adiposity and blood pressure in male adolescents. Hypertension 55: 706-714. 